05

\title{
Исследование модификации структуры и эрозии поверхности вольфрама и молибдена при плазменном облучении
}

\author{
( Б.К. Рахадилов, ${ }^{1,3}$ А.Ж. Миниязов, ${ }^{1}$ М.К. Скаков, ${ }^{2}$ Ж.Б. Сагдолдина, ${ }^{3}$ Т.Р. Туленбергенов, ${ }^{1}$ Е.Е. Сапатаев ${ }^{1}$ \\ ${ }^{1}$ Филиал „Институт атомной энергии Национального ядерного центра Республики Казахстан“, \\ 071100 Курчатов, Казахстан \\ ${ }^{2}$ Национальный ядерный центр Республики Казахстан, \\ 071100 Курчатов, Казахстан \\ ${ }^{3}$ Восточно-Казахстанский государственный университет им. Сарсена Аманжолова, \\ 070002 Усть-Каменогорск, Казахстан \\ e-mail: miniyazov@nnc.kz
}

Поступило в Редакцию 14 июня 2019 г.

В окончательной редакции 14 июня 2019 г.

Принято к публикации 3 сентября 2019 г.

\begin{abstract}
Приведены результаты исследования модификации структуры и эрозии поверхности вольфрама и молибдена при облучении плазмой. Выявлено, что при облучении образцов наблюдается изменение поверхности в виде развития рельефа в результате неоднородного травления поверхности. Металлографический анализ показал, что при облучении образцов вольфрама при 1000 и $1500^{\circ} \mathrm{C}$ степень развития рельефа невысокая по сравнению с образцом вольфрама, облученного при $700^{\circ} \mathrm{C}$. Определено наибольшее увеличение шероховатости у образцов, облученных при $1500^{\circ} \mathrm{C}$, что связано с образованием мелких трещин в приповерхностном слое. Установлено, что заметная эрозия образцов вольфрама и молибдена в результате облучения имитирующими стационарный режим потоками плазмы наступает только при относительно высоких температурах мишени. Установлено, что с увеличением энергии ионов от 1.5 до $2 \mathrm{keV}$ увеличивается размер трещин. Обнаружено, что в результате облучения вольфрама стационарной плазмой в теле зерна образуются ямки травления размером от 100 до $500 \mathrm{~nm}$, а при облучении с ускоряющим потенциалом $1.6 \mathrm{keV}$ формируется большое количество мелких пор размером от 0.2 до $1.0 \mu \mathrm{m}$ как результат вытравливания поверхности.
\end{abstract}

Ключевые слова: плазменное облучение, вольфрам, молибден, дивертор, плазменно-пучковая установка.

DOI: 10.21883/JTF.2020.03.48923.243-19

\section{Введение}

Одной из ключевых задач в создании термоядерного реактора на основе токамака является выбор обращенных к плазме материалов, которые должны противостоять как стационарному, так и интенсивному импульсному плазменно-тепловому воздействию. Изучение особенностей воздействия ядерно-физических излучений на конденсированные среды вызывает повышенное внимание исследователей, занимающихся изучением фундаментальных закономерностей взаимодействия заряженных частиц с твердыми телами с различной электронной структурой [1-3]. Большое значение имеют исследования явлений, связанных с изменением структуры поверхности материалов первой стенки и диверторных пластин термоядерных установок под воздействием плазменных пучков [4]. Результатом воздействия плазмы на материал являются распыление и испарение материала, изменение структуры и фазового состояния, образование на поверхности новых химических соединений и т.д. [5]. Сложность и многофакторность взаимодействия плазмы термоядерного реактора с материалами, а также дороговизна натурных испытаний на полномасштабных установках определяют необходимость проведения таких экспериментов с использованием малых специализированных имитационных установок.

Важными задачами термоядерной энергетики являются минимизация эрозии материалов как при нормальной работе, так и во время переходных событий, а также соответствующий выбор этих материалов [6].

В настоящее время наиболее перспективными материалами, обращенными к плазме, являются вольфрам и молибден, которые обладают комплексом уникальных физических свойств: низкий коэффициент физического распыления, высокая температура плавления, высокая теплопроводность, низкое накопление трития. С учетом высоких тепловых нагрузок на диверторную мишень в стационарном режиме необходимость экспериментального исследования модификации поверхности этих материалов при воздействии стационарной плазмы приобретает особую важность.

В связи с этим целью настоящей работы является исследование особенности эрозии поверхностей вольфрама и молибдена под воздействием водородной плазмы на имитационном стенде с плазменно-пучковой установкой. 


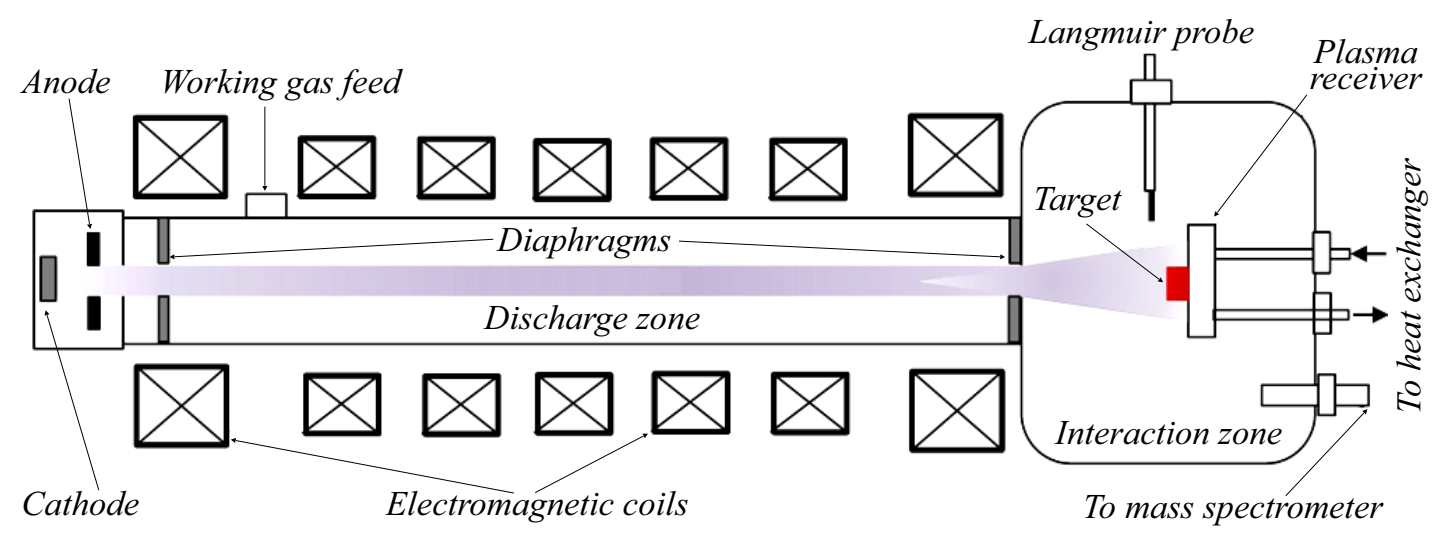

Рис. 1. Схематическое изображение плазменно-пучковой установки.

Значения параметров облучения вольфрама и молибдена водородной плазмой

\begin{tabular}{|c|c|c|c|c|c|c|c|c|c|c|}
\hline 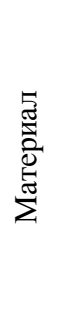 & 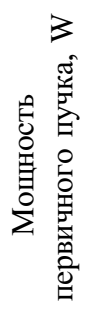 & 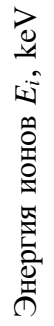 & 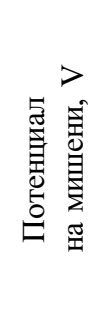 & 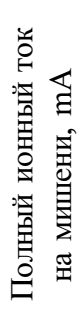 & 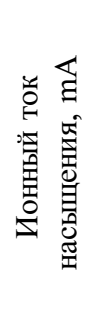 & 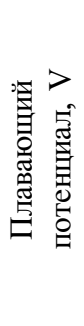 & 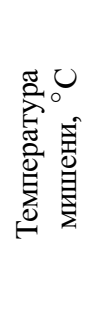 & $\begin{array}{l}\stackrel{\Xi}{\Xi} \\
\sim\end{array}$ & 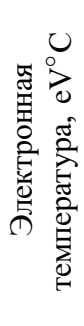 & 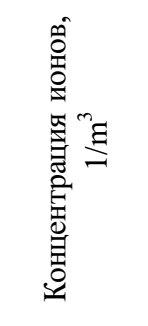 \\
\hline $\mathrm{W}$ & 240 & 2.0 & -2000 & 230 & 5.5 & -22 & 700 & 180 & 6.4 & $1.46 \cdot 10^{17}$ \\
\hline $\mathrm{W}$ & 260 & 2.0 & -2000 & 275 & 7.3 & -18 & 1000 & 180 & 7.9 & $1.54 \cdot 10^{17}$ \\
\hline $\mathrm{W}$ & 850 & 2.0 & -2000 & 350 & 8.2 & -15 & 1500 & 180 & 8.8 & $2.02 \cdot 10^{17}$ \\
\hline $\mathrm{W}$ & 240 & 1.5 & -1500 & 220 & 4.5 & -22 & 1000 & 180 & 5.5 & $1.17 \cdot 10^{17}$ \\
\hline Mo & 810 & 2.0 & -2000 & 340 & 8.5 & -12 & 1500 & 180 & 8.4 & $1.89 \cdot 10^{17}$ \\
\hline $\mathrm{W}$ & 2500 & 1.2 & -1200 & 280 & 6.0 & -17 & 1000 & 60 & 4.97 & $2.69 \cdot 10^{17}$ \\
\hline $\mathrm{W}$ & 2500 & 1.6 & -1600 & 320 & 6.0 & -15 & 1000 & 60 & 4.28 & $2.86 \cdot 10^{17}$ \\
\hline
\end{tabular}

\section{Методы исследования и оборудование}

Испытания материалов под воздействием плазмы проводились на имитационном стенде с плазменно-пучковой установкой (ППУ), разработанный в филиале „Институт атомной энергии“ Национального ядерного центра Республики Казахстан (ИАЭ НЯЦ РК) [7,8]. Стенд был создан для проведения поддерживающих экспериментальных исследований, проводимых на Казахстанском материаловедческом токамаке (КТМ) в виде испытаний маломасштабных образцов материалов и оборудования КТМ. ППУ является универсальной установкой и позволяет проводить испытание материалов в условиях комплексного воздействия на них как плазменного потока, так и мощной тепловой нагрузки, создаваемой с помощью электронного пучка. Использование ППУ дает возможность оперативно получать предварительные экспериментальные данные о поведении материалов в условиях взаимодействия их с плазмой при высокой тепловой нагрузке, что позволит внести коррективы в методологию экспериментальных исследований на КTM [9].
Основными элементами ППУ являются электроннолучевая пушка (ЭЛП), камера плазменно-пучкового разряда, камера откачки ЭЛП, вакуумная камера взаимодействия, катушки ЭЛП, мишенное устройство, шлюзовое устройство и камера загрузки. Схематическое изображение установки приведено на рис. 1. Установка обеспечивает получение следующих параметров плазменного потока: диаметр плазменного потока перед мишенью до $30 \mathrm{~mm}$; напряженность магнитного поля, создаваемая на оси ЭЛП $0.1 \mathrm{~T}$; напряженность магнитного поля в районе ЭЛП $0.01 \mathrm{~T}$; величина тока в плазме около $1 \mathrm{~A}$; плотность потока плазмы в пучке до $10^{22} \mathrm{~m}^{-2} \cdot \mathrm{s}^{-1}$; электронная температура плазмы до $100 \mathrm{eV}$.

Принцип работы установки состоит в следующем. Электронная пушка формирует аксиальносимметричный электронный пучок. Далее катод пушки подогревается электронной бомбардировкой с нити подогревателя. При этом мощность пушки регулируется мощностью подогрева катода. Автономное вакуумирование пушки обеспечивает перепад давлений между пушкой и разрядной камерой. Система дифференциальной откачки, включающая турбомолекулярные и фор- 

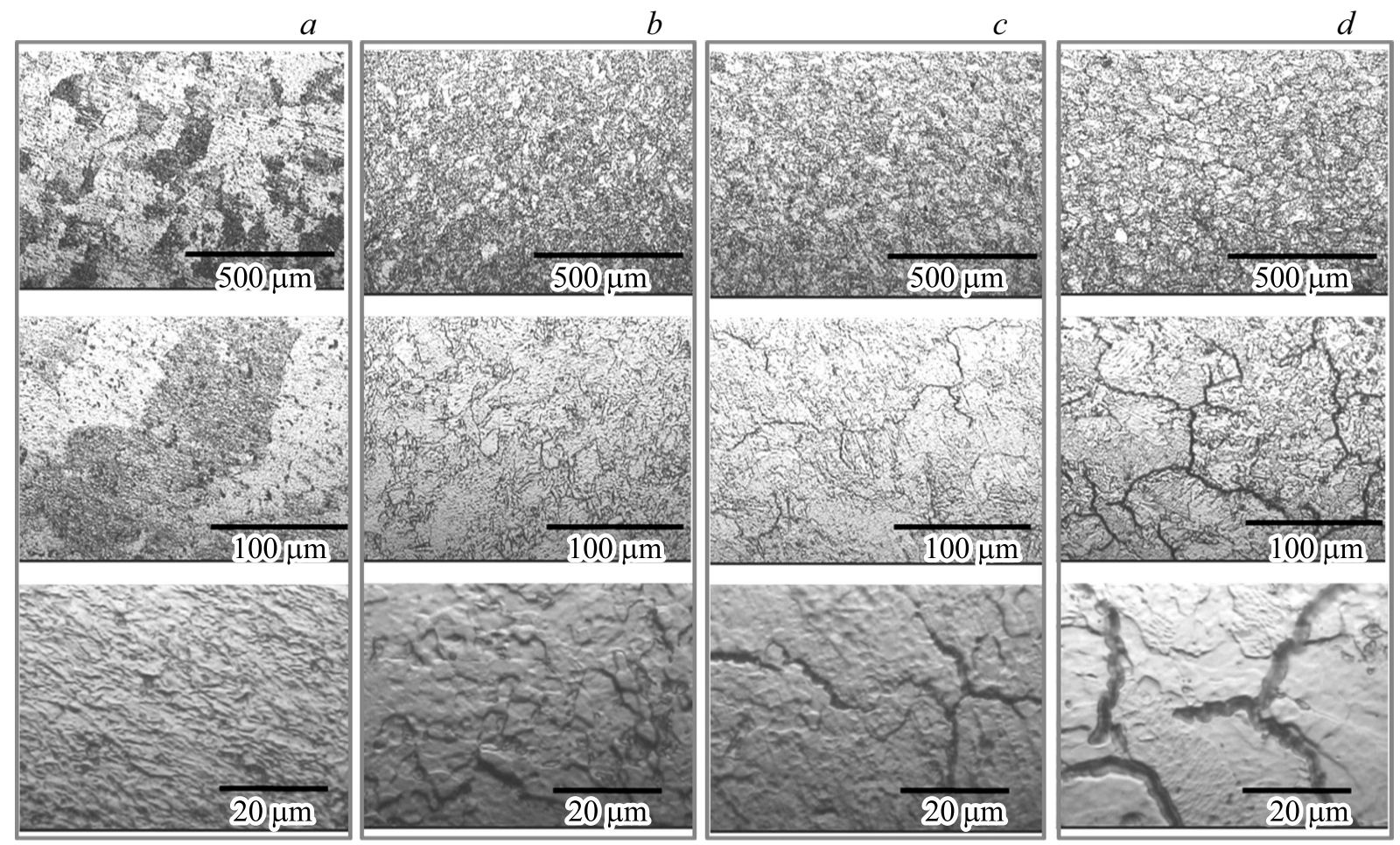

Рис. 2. Микроструктура поверхности вольфрама до $(a)$ и после облучения водородной плазмой при $T=700(b), 1000(c)$ и $1500^{\circ} \mathrm{C}(d)$.

вакуумные насосы, обеспечивает необходимое давление газа в различных отсеках установки. Параметры плазмы измеряются электрическим зондом Ленгмюра, размещенным в зоне взаимодействия. Контроль среды в полости камеры взаимодействия осуществлялся при помощи квадрупольного масс-спектрометра CIS-100.

Фокусировка электронного и плазменного пучков происходит в разрядной камере при помощи электромагнитной системы. Электромагнитная система, представляющая собой систему катушек, создает продольное магнитное поле в разрядной камере. Снижение или увеличение электрического тока, протекающего по электромагнитным катушкам, приводит к снижению или увеличению напряженности магнитного поля в камере плазменно-пучкового разряда, которая в свою очередь определяет диаметр пучка. Электронный пучок взаимодействует с рабочим газом в разрядной камере, образуя плазменный шнур. Плазменный разряд попадает на образец испытываемого материала, который размещен на мишенном устройстве в камере взаимодействия.

Облучение поверхности твердых тел ионными и плазменными потоками вызывает те или иные изменения рельефа. В зависимости от параметров облучающего потока и условий на поверхности эти изменения проявляются как в развитии, так и в сглаживании рельефа. В случае плазменного облучения создание рельефа травления на поверхностях металлов и сплавов определяется ионной компонентой. Также характер эрозии материалов существенным образом зависит от рабочего диапазона температур. В связи с этим в настоящей работе по облучению вольфрама водородной плазмой варьируются температура и энергия ионов.

Экспериментальные исследования особенностей модификации поверхностей вольфрама и молибдена под воздействием водородной плазмы проводились в режиме пучково-плазменного разряда. При этом варьировались температура мишени и энергия плазменного пучка (см. таблицу). Облучение образцов осуществлялось плазмой с энергией ионов $1.2-2.0 \mathrm{keV}$ длительностью до $180 \mathrm{~min}$. Во время облучения давление в камере составило $2 \cdot 10^{-3}$ Torr. В качестве рабочего газа использовался водород особой чистоты.

В качестве материалов исследования были выбраны вольфрам марки ВЧ и молибден марки МЧ. Заготовки образцов для исследований в виде циллиндра диаметром $10 \mathrm{~mm}$ изготавливались из прутков. Вырезка образцов выполнялась на электроискровом станке модели 4531, в качестве электрода использовалась латунная проволока диаметром $0.3 \mathrm{~mm}$. При резке образцы не испытывали деформацию и термическое воздействие.

Шлифы для исследований были изготовлены по стандартной методике, включающей механическое шлифование и полирование. Для выявления микроструктуры вольфрама использовали химическое травление в растворе, содержащем 50\% плавиковой кислоты и 50\% азотной кислоты. 


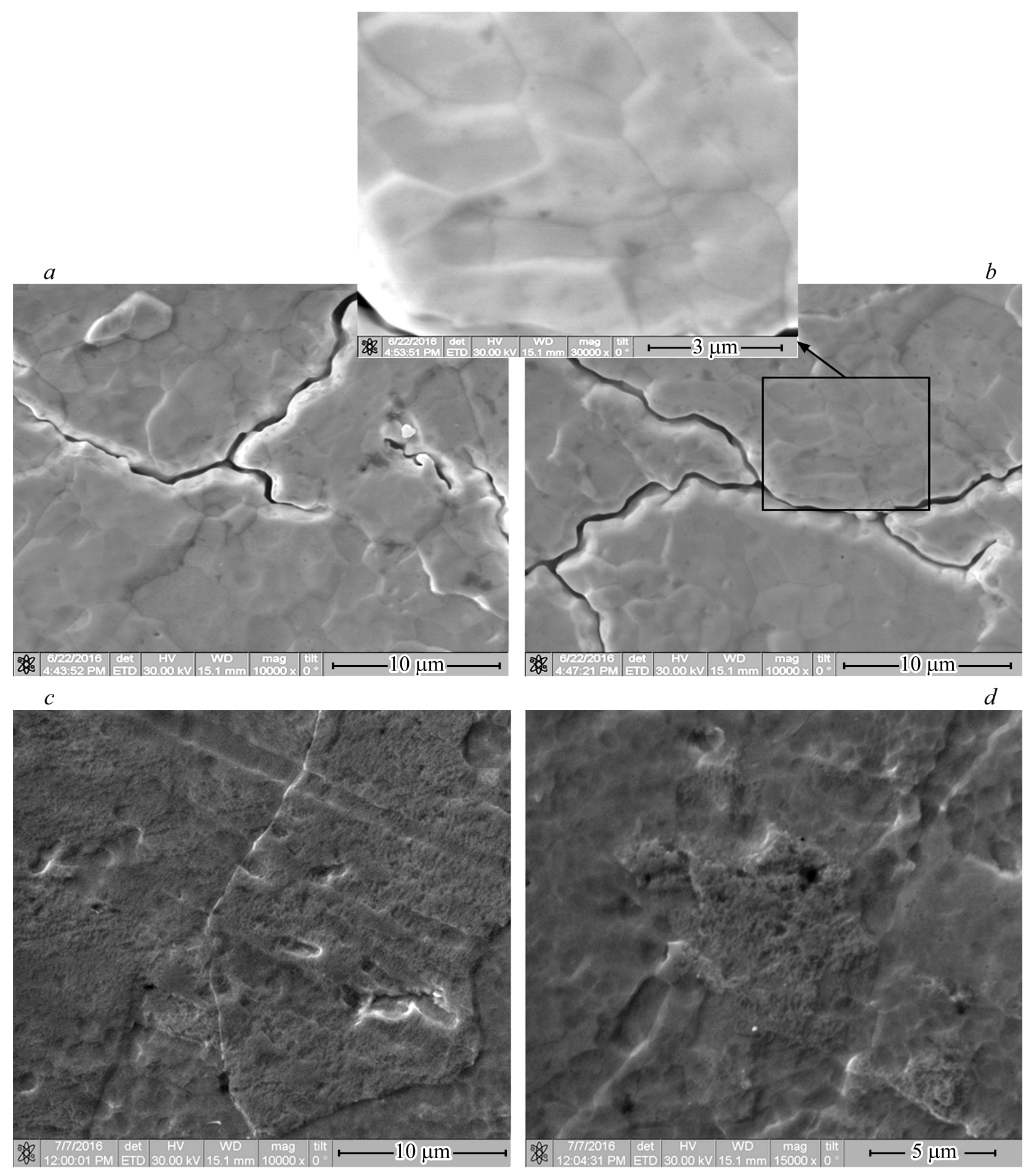

Рис. 3. СЭМ изображения поверхности вольфрама $(a, b)$ и молибдена $(c, d)$ облученных водородной плазмой при $T=1500^{\circ} \mathrm{C}$.

Для проведения металлографического анализа исследуемых материалов применялся оптический световой микроскоп OLIMPUS BX41M [10]. Микроструктуру и элементный состав образцов до и после облучения исследовали на сканирующем электронном микроскопе JSM-6390 с приставкой энергодисперсионного микроанализа JED-3000. Для изучения тонкой структуры по- верхностного слоя использовался просвечивающий электронный микроскоп JEM-2100 с системой энергодисперсионного микро- и наноанализа $[11,12]$. Исследования проводились методом дифракционной электронной микроскопии тонких фольг при ускоряющем напряжении $125 \mathrm{kV}$. Рабочее увеличение в колонне микроскопа выбиралось от 10000 до 80000 . 


\section{Результаты исследования}

На рис. 2 показана структура поверхности вольфрама, облученного водородной плазмой при разных температурах.

Из рисунка видно, что облучение при температуре $T=700^{\circ} \mathrm{C}$ вызывает на поверхности материала развитие рельефа. Образующийся рельеф состоит из хаотически расположенных выступов и впадин различных форм. Развитие рельефа на поверхности вольфрама за счет разных скоростей эрозии соседних участков при плазменном
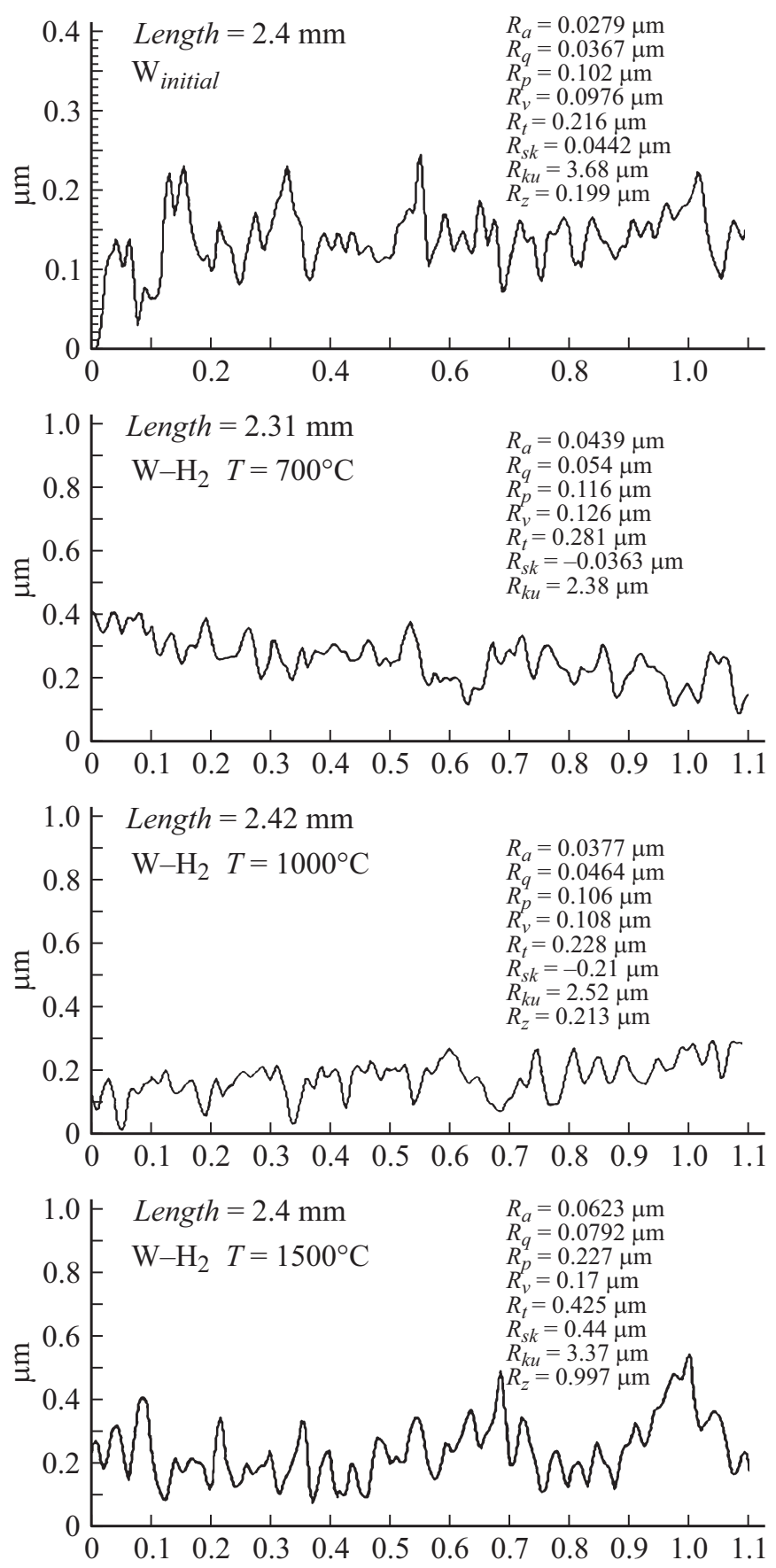

Рис. 4. Результаты исследований на оптическом профилометре.

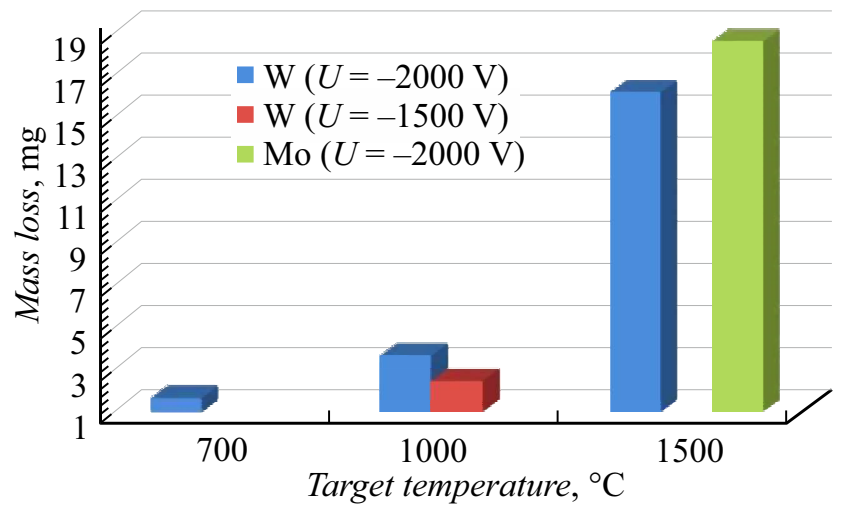

Рис. 5. Зависимость потери массы вольфрама и молибдена от температуры облучения водородной плазмой.

облучении связано с тем, что различным образом ориентированные поверхностные кристаллы характеризуются различными коэффициентами распыления [13,14].

Анализ экспериментальных результатов показал, что степень изменения рельефа и структуры поверхностного слоя облученных образцов зависит от вида материала и параметров облучения. По данным металлографического анализа при облучении образцов вольфрама в диапазоне $T=$ от 700 до $1500^{\circ} \mathrm{C}$ сохраняется динамика развития рельефа. В этих образцах наблюдаются мелкие трещины, при этом с ростом температуры до $1500^{\circ} \mathrm{C}$ размер и количество трещин увеличиваются.

На рис. 3 приведены СЭМ изображения поверхности вольфрама $(a, b)$ и молибдена $(c, d)$, облученных водородной плазмой при $T=1500^{\circ} \mathrm{C}$.

Топография облученных поверхностей вольфрама и молибдена свидетельствует об их сильной эрозии. В результате взаимодействия с водородной плазмой произошло травление поверхности вольфрама и молибдена, проявление границ зерен и их ориентации. Также из рисунков видно, что при одинаковых режимах облучения при $T=1500^{\circ} \mathrm{C}$ на поверхности молибдена не образуются мелкие трещины, что говорит о более высокой трещиностойкости молибдена по сравнению с вольфрамом. В этом случае рельеф поверхности молибдена менее развит.

Результаты исследования образцов на оптическом профилометре показаны на рис. 4. Определено, что после облучения водородной плазмой изменяется шероховатость поверхности в зависимости от температуры облучения. Наибольшее увеличение шероховатости $R_{a}=0.0623 \mu \mathrm{m}$ наблюдается в образцах, облученных при $T=1500^{\circ} \mathrm{C}$, что связано с образованием мелких трещин на поверхностном слое. При этом в образцах, облученных при $T=700^{\circ} \mathrm{C}$, поверхность которых характеризуется хаотично расположенными выступами и впадинами различных форм, параметр шероховатости $R_{a}$ составил $0.0439 \mu \mathrm{m}$. Наименьшее изменение шероховатости $R_{a}=0.0377 \mu$ m наблюдается в образцах, облученных при $T=1000^{\circ} \mathrm{C}$. Полученные результаты 

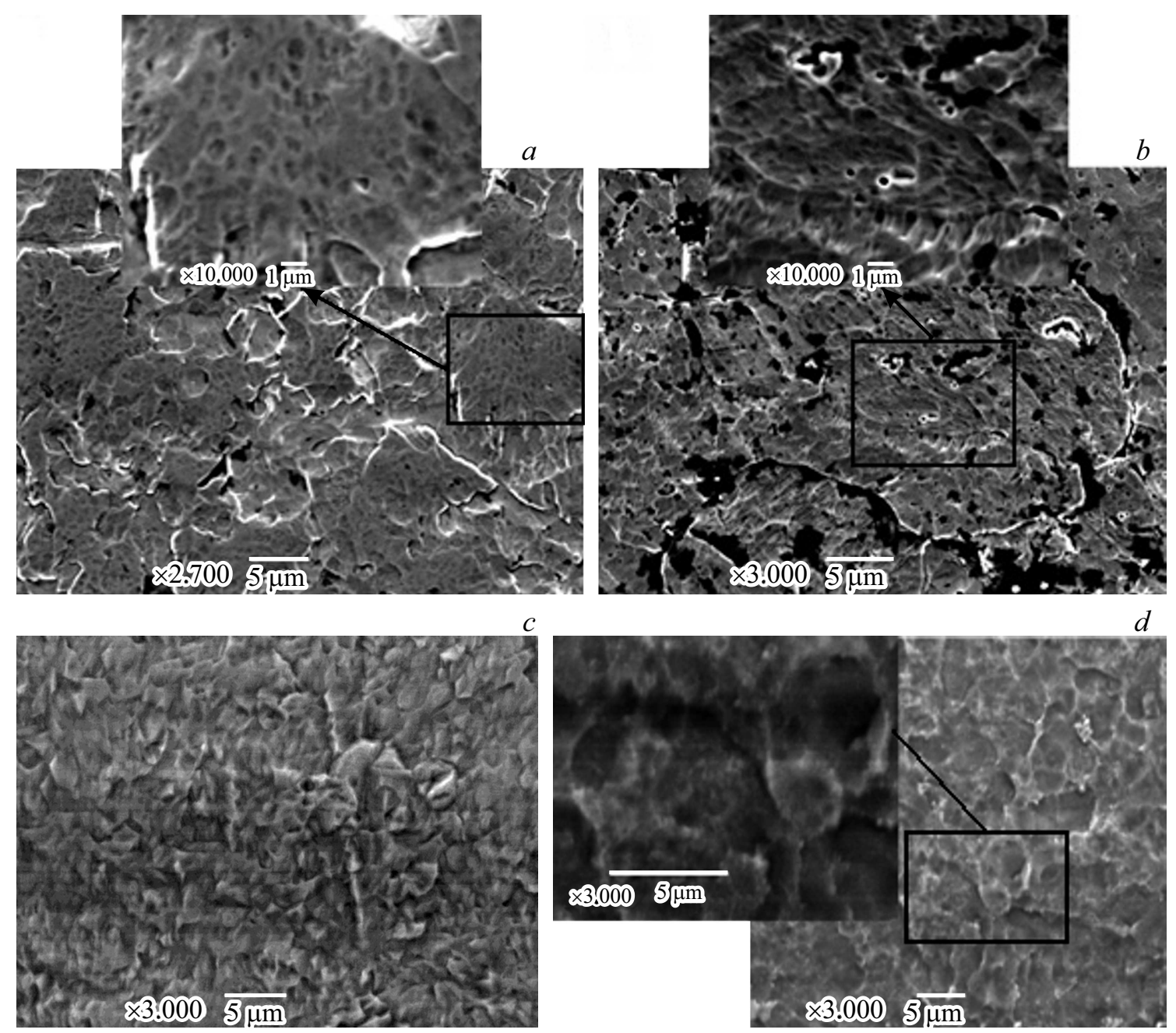

Рис. 6. СЭМ изображение поверхности образцов вольфрама: $a-P=2.5 \mathrm{~kW}, U=-1200 \mathrm{~V}, b-P=2.5 \mathrm{~kW}, U=-1600 \mathrm{~V}$; и молибдена: $c-$ исходный, $d-P=2.5 \mathrm{~kW}, U=-1200 \mathrm{~V}$ после облучения плазменным пучком в среде водорода.

хорошо согласуются с результатами металлографического анализа.

Таким образом, можно утверждать, что при облучении вольфрама и молибдена водородной плазмой основным рельефообразующим механизмом является распыление поверхности, характеризующееся термическим травлением поверхности.

Эрозия образцов вольфрама и молибдена оценивалась методом взвешивания образцов до и после облучения. На рис. 5 показана зависимость потери массы вольфрама от режима облучения водородной плазмой. Из рисунка видно, что с повышением температуры облучения степень эрозии увеличивается, что вполне закономерно. Известно [15], что в случае облучения металлов и сплавов ионами и плазмой инертных газов при температурах выше температуры отжига элементарных дефектов, созданных облучением, формирование рельефа происходит в основном благодаря распылению поверхности за счет кинетической энергии ионов по каскадному механизму.
Таким образом установлено, что механизм эрозии зависит от природы твердого тела и условий облучения.

Полученные результаты показали, что с увеличением температуры мишени и энергии ионов увеличивается степень эрозии поверхности. Результаты воздействия потоков плазмы на материал определяются в основном удельной мощностью падающего потока.

В силу своих теплофизических свойств, заметная эрозия вольфрама в результате облучения потоками плазмы, имитирующими стационарный режим плазмы, наступает только при относительно жестких условиях. Кроме того, при жестком воздействии наблюдается поверхностное растрескивание вследствие возникновения значительных термонапряжений из-за градиента температур по толщине мишени.

Были проведены экспериментальные исследования влияния облучения водородной плазмой на микроструктуру вольфрама и молибдена. С помощью сканирующей электронной микроскопии (СЭМ) была исследована структура вольфрамовых образцов после об- 

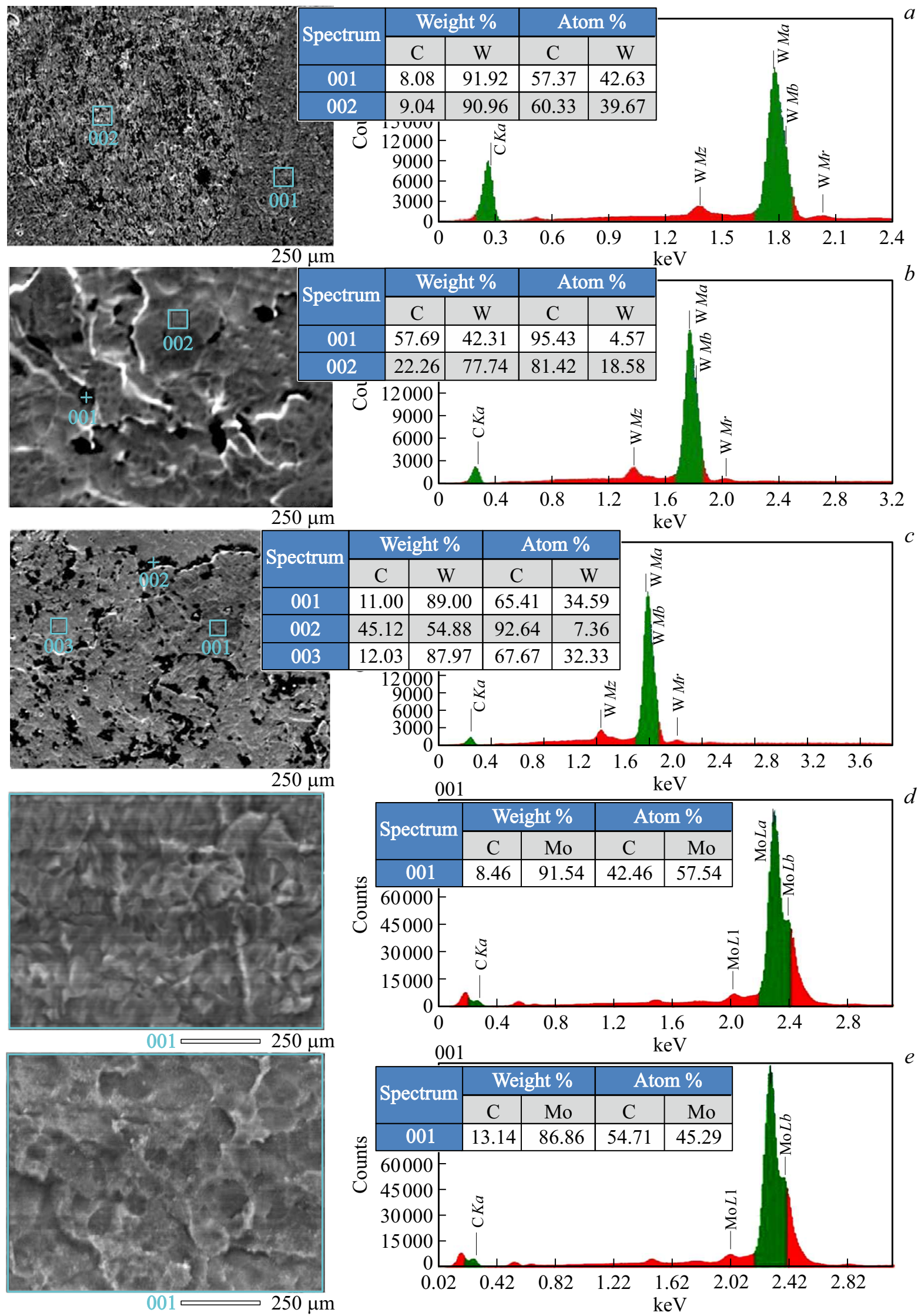

Рис. 7. Результаты рентгеноспектрального микроанализа исходной $(a-\mathrm{W}, d-\mathrm{Mo})$ и облученной $(b-\mathrm{W}, P=2.5 \mathrm{~kW}$, $U=-1200 \mathrm{~V}, c-\mathrm{W}, P=2.5 \mathrm{~kW}, U=-1600 \mathrm{~V}, e-\mathrm{Mo}, P=2.5 \mathrm{~kW}, U=-1600 \mathrm{~V})$ поверхности образцов вольфрама и молибдена. 


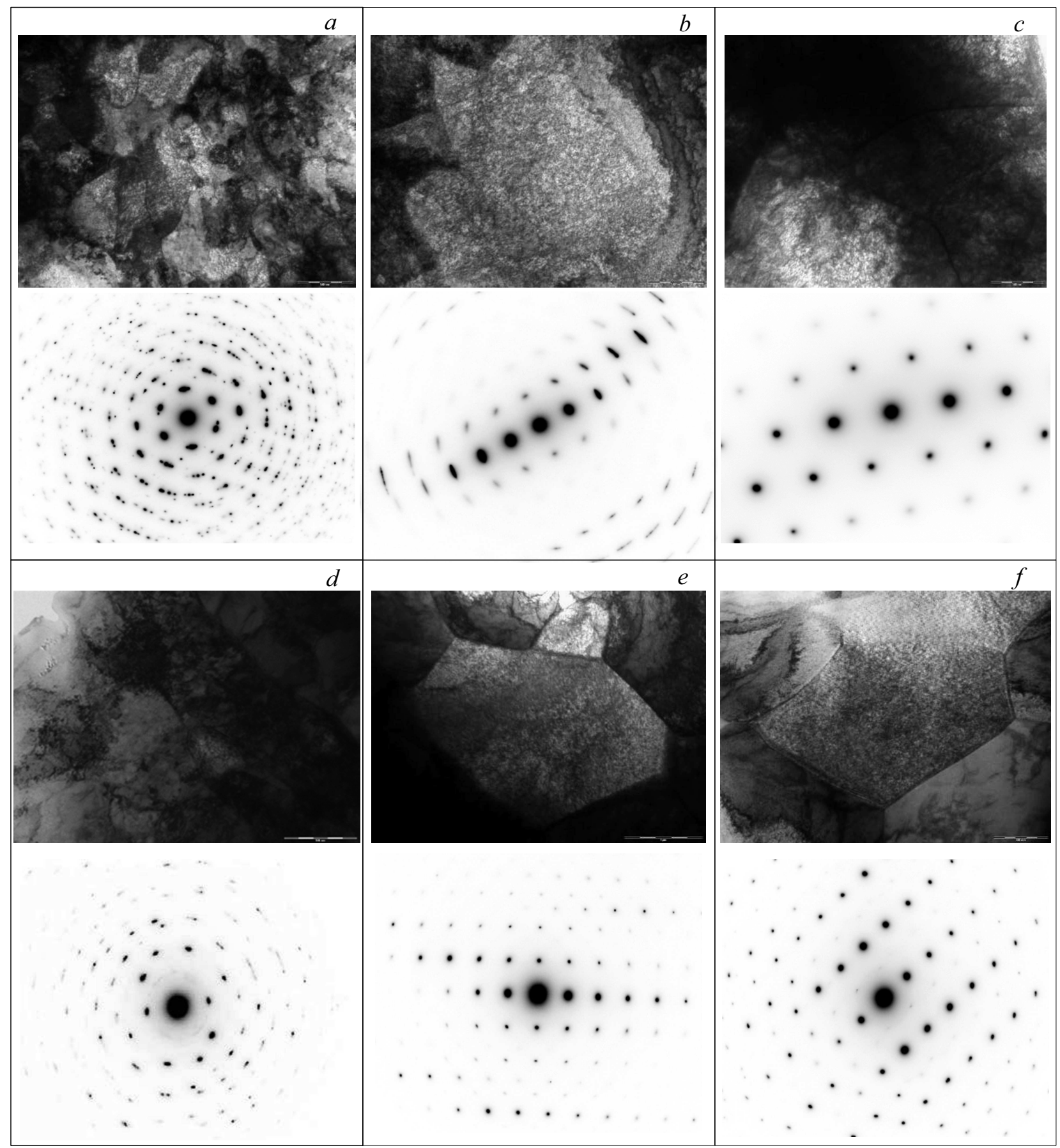

Рис. 8. Электронно-микроскопические изображения тонкой структуры поверхности вольфрама и молибдена до и после облучения гелиевой и водородной плазмой при мощности первичного пучка $2.5 \mathrm{~kW}$ и ускоряющем потенциале $-1600 \mathrm{~V}$ и их микродифракции: $a-\mathrm{W}$ исходный, $b-\mathrm{W}$, гелиевая плазма, $c-\mathrm{W}$, водородная плазма, $d-$ Мо исходный, $e-$ Мо, гелиевая плазма, $f-$ Мо, водородная плазма.

лучения водородной плазмой при мощности первичного пучка $2.5 \mathrm{~kW}$ с энергией ионов 1.2 и $1.6 \mathrm{keV}$ (рис. 6). Обнаружено, что поверхность вольфрама эродирует при облучении водородной плазмой с энергией ионов $1.2 \mathrm{keV}$. При этом происходит изменение рельефа и на поверхности образуются ямки травления размером от 100 до $500 \mathrm{~nm}$ за счет бомбардировки ионами водорода. Это связано с тем, что при взаимодействии твердого тела и ускоренных ионов с энергией, превышающей энергию распыления, на поверхности твердого тела происходит ряд процессов упругого и неупругого взаимодействия. На границе раздела „газ-твердое тело“ протекают химические реакции, приводящие к изменению физико-химических свойств относительно тонкого 
поверхностного слоя массивного тела, т.е. происходит модификация структуры и соответственно свойств поверхности. Вследствие упругих и неупругих взаимодействий иона с энергией, превышающей энергию распыления, происходит распыление атомов мишени или подложки (процесс травления).

После облучения при потенциале $-1600 \mathrm{~V}$ наблюдалась сглаженная поверхность с микродефектами. Возможно, это связано с тем, что повышение ускоряющего потенциала от -1200 до $-1600 \mathrm{~V}$ приводит к уменьшению процесса распыления и увеличению внедрения ионов, так как при высоких уровнях энергии над процессом распыления начинает преобладать глубинное проникновение ионов - ионная имплантация и объемные нарушения, т.е. происходит усиление дефектообразования. Процесс дефектообразования начинается при энергиях около $50 \mathrm{eV}$ и сопровождает процесс распыления $[14,16]$. В частности, при облучении при ускоряющем потенциале $-1600 \mathrm{~V}$ образуется большое количество мелких пор размером от 0.2 до $1.0 \mu \mathrm{m}$. Система трещин и пор создает транспортный путь между поверхностью и объемом материала, поэтому можно ожидать глубокого проникновения ионов в объем металла. Причинами появления этих структурных нарушений, по-видимому, являются механические напряжения в решетке вольфрама, вызванные имплантированным водородом. Микроструктура молибдена до и после облучения водородной плазмой при мощности первичного пучка $2.5 \mathrm{~kW}$ без потенциала и с потенциалом на мишень $-1600 \mathrm{~V}$ представлена на рис. $6, c, d$. Металлографический анализ показал, что после облучения водородной плазмой не наблюдаются значимых изменений микроструктуры поверхности молибдена. С целью изучения изменения элементного состава поверхности вольфрама и молибдена после облучения плазменным пучком был проведен рентгеноспектральный микроанализ поверхности, результаты которого на рис. 7.

Анализ показал, что в составе поверхности вольфрама в исходном состоянии и после облучения помимо вольфрама наблюдается углерод, массовая доля которого составляет от 8 до $60 \%$. Такое сравнительно большое количество углерода связано с тем, что в камере микроскопа находился остаточный газ, содержащий углерод. При облучении водородной плазмой на поверхности накапливается водород, однако рентгеноспектральным микроанализом не удается определить легкие элементы с порядковым номером меньше 4. На рис. 7 видны характерные признаки, отличающие облученную поверхность - присутствие на ней темных пятен микронного масштаба. Анализ структуры этих пятен показывает, что они представляют собой ямки, обагашенные углеродом, образующиеся в результате воздействия плазмы.

Тонкая структура вольфрама (рис. $8, a-c$ ) и молибдена (рис. $8, d-f$ ), наблюдаемая методом просвечивающей электронной микроскопии, представлена на рис. 8 .

Хорошо видно, что после облучения структура вольфрама более фрагментирована и характеризуется дефектной субструктурой. Образующаяся дефектность приближается к дефектности границ зерен. Возможность формирования такой субструктуры зерен при электронно-лучевой обработке обеспечивается повышенным энергетическим состоянием поверхности и подповерхностных слоев, подвергаемых на всем протяжении обработки бомбардировке ионами и нейтральными атомами низкотемпературной плазмы. На рис. $8(d-f)$ показаны электронно-микроскопические изображения тонкой структуры молибдена до и после облучения гелиевой и водородной плазмой. Обнаружено, что после облучения в поверхностном слое молибдена наблюдается фрагментированная субструктура. На границе зерен наблюдаются мелкие дефекты.

\section{Заключение}

Анализируя полученные в работе результаты, можно сделать следующие выводы:

- установлено, что при облучении вольфрама и молибдена водородной плазмой основным рельефообразующим механизмом является распыление поверхности, при этом эрозия характеризуется термическим травлением поверхности;

- выявлено, что степень изменения рельефа и структуры поверхностного слоя облученных образцов зависит от вида материала и параметров облучения;

- металлографический анализ показал, что при облучении образцов вольфрама при $T=1000$ и $1500^{\circ} \mathrm{C}$ степень развития рельефа невысокая по сравнению с образцом вольфрама, облученного при $T=700^{\circ} \mathrm{C}$. В этих образцах наблюдаются мелкие трещины, при этом с ростом температуры до $1500^{\circ} \mathrm{C}$ размер и количество трещин увеличиваются. А при одинаковых режимах облучения при $T=1500^{\circ} \mathrm{C}$ на поверхности молибдена не образуются мелкие трещины, что говорит о более высокой трещиностойкости молибдена по сравнению с вольфрамом;

- определено, что с увеличением энергии ионов с 1.5 до $2 \mathrm{keV}$ увеличивается размер трещин, на поверхности образуются выступы и впадины, повторяющие форму кристаллитов;

- установлено, что с увеличением температуры мишени и энергии ионов увеличивается степень эрозии поверхности;

— определено, что облучение водородной плазмой при мощности первичного пучка $2 \mathrm{~kW}$ не приводит к сильным изменениям микроструктуры поверхности вольфрама. А при облучении водородной плазмой с мощностью первичного пучка $2.5 \mathrm{~kW}$ при потенциале мишени -1200 и $-1600 \mathrm{~V}$ наблюдается уменьшение размеров зерен, выявляются границы зерна за счет травления поверхности ионами водорода и наблюдаются мелкие дефекты;

- обнаружено, что в результате облучения вольфрама стационарной плазмой в теле зерна образуются ямки 
травления размером от 100 до $500 \mathrm{~nm}$, как результат вытравливания поверхности. Помимо этого в объеме вольфрама создаются микротрещины и поры. В частности, при облучении при ускоряющем потенциале $-1600 \mathrm{~V}$ формируется большое количество мелких пор размером от 0.2 до $1.0 \mu \mathrm{m}$;

- выявлено, что после облучения структура вольфрама становится более фрагментированной и характеризуется более развитой дефектной субструктурой. Образующаяся дефектность приближается к дефектности границ зерен. Причиной появления этих структурных нарушений, по-видимому, являются механические напряжения в решетке вольфрама, вызванные имплантированными ионами;

- обнаружено, что после облучения водородной и гелиевой плазмой в поверхностном слое молибдена формируется фрагментированная субструктура. На границе зерен наблюдаются мелкие дефекты;

- определено, что с увеличением энергии ионов и температуры облучения наблюдается увеличение степени разрушения образцов вольфрама и молибдена. При этом при $T=1000^{\circ} \mathrm{C}$ на поверхности образца вольфрама образуются трещины небольшим сечением. А при увеличении температуры до $1500^{\circ} \mathrm{C}$ на поверхности наблюдаются трещины с большим сечением. На этих трещинах наблюдаются мелкие частицы, представляющие собой распыленные частицы вольфрама, переосажденные на эти трещины.

\section{Финансирование работы}

Настоящая работа выполнена при финансовой поддержке Комитета науки Министерства образования и науки Республики Казахстан в рамках Грантового финансирования научного проекта на тему „Экспериментальное моделирование взаимодействия плазмы с кандидатными материалами термоядерного реактора“.

\section{Конфликт интересов}

Авторы заявляют, что у них нет конфликта интересов.

\section{Список литературы}

[1] Kurnaev V., Kolodeshnikov A., Tulenbergenov T., Sokolov I. // J. Nucl. Mater. 2015. Vol. 463. P. 228-232.

[2] Roth J., Tsirone E., Loarte A., Loarer Th., Counsell G., Neu R., Philipps V., Brezinsek S., Lehnen M., Coad P., Grisolia Ch., Schmid K., Krieger K., Kallenbach A., Lipschultz B., Doerner R., Cousey R., Alimov V., Shu W., Ogorodnikova O., Kirschner A., Federici G., Kukushkin A. // J. Nucl. Mater. 2009. Vol. 390-391. P. 1-9. doi.org/10.1016/j.jnucmat.2009.01.037

[3] Klepikov A.K., Tazhibaeva I.L., Shestakov V.P., Romanenko O.G., Chikhray Y.V., Cherepnin Yu.S., Tikhomirov L.N. // J. Nucl. Mater. 1996. Vol. 233-237. Part 2. P. 837-840. https://doi.org/10.1016/S0022-3115(96)00039-6
[4] Будаев В.П. Результаты испытаний вольфрамовых мишеней дивертора при мощных плазменно-тепловых нагрузках, ожидаемых в ИТЭР и токамаках реакторного масштаба / ВАНТ. Сер. Термоядерный синтез. 2015. Т. 38. № 4. C. 5-33.

[5] Report of ITER Joint Central Team, G AO FDR 4 01-07-21 R0.4 Garching, 2001. P. 80.

[6] Philipps V., Roth J., Loarte A. // Plasma Phys. Controlled Fusion. 2003. Vol. 45. P. 17-30.

[7] Стенд имитационных испытаний в сопровождение исследований на токамаке КТМ (СИИ-КТМ): итоговый отчет: 85-3-021-129: Ч. 1. М.: МИФИ. 2005. 46 с.

[8] Соколов И.А., Скаков М.К., Зуев В.А., Гановичев Д.А., Туленбергенов Т.Р., Миниязов А.Ж. // ЖТФ. 2018. Т. 88. Вып. 4. C. 521-525.

[9] Sadykov A.D., Suchugov D.Yu., Shapovalov G.V., Chektybaev B.Zh., Skakov M.K., Gasilov N.A. // Nucl. Fusion. 2015. Vol. 55. N 4. org/10.1088/0029-5515/55/4/043017

[10] Салтыков С.A. Стереометрическая металлография. М.: Металлургия, 1976. 190 с.

[11] Электронограммы и их интерпретация / К. Эндрюс, Д. Дайсон, С. Киоун. М.: Мир, 1971. 256 с.

[12] Барсуков В.И. Пламенно-эмиссионные и атомноабсорбционные методы анализа и инструментальные способы повышения их чувствительности. М.: Изд-во Маш-1, 2004. 72 c.

[13] Rahadilov B.K., Skakov M.K., Tulenbergenov T.R. // Key Engineer. Mater. 2017. Vol. 736. P. 46-51.

[14] Рахадилов Б.К., Скаков М.К. Эрозия поверхности вольфрама и бериллия при воздействии стационарного плазменного потока. Тезисы XI Междунар. конф. „Ядерная и радиационная физика, Алматы, 12-15 сентября 2017 г.“, Алматы, ИЯФ, 2017. С. 241.

[15] Беграмбеков Л.Б. Модификация поверхности твердых тел при ионном и плазменном воздействии: учебн. пособие. М: МИФИ, 2001. $22 \mathrm{c}$.

[16] Rakhadilov B., Skakov M., Miniyazov A., Kenesbekov A. Hydrogen and deuterium storage in tungsten when irradiation with plasma beam, METAL 2018 - 27th Intern. Conf. on Metallurgy and Materials, Conference Proceedings, 2018. P. 1216-1221. 